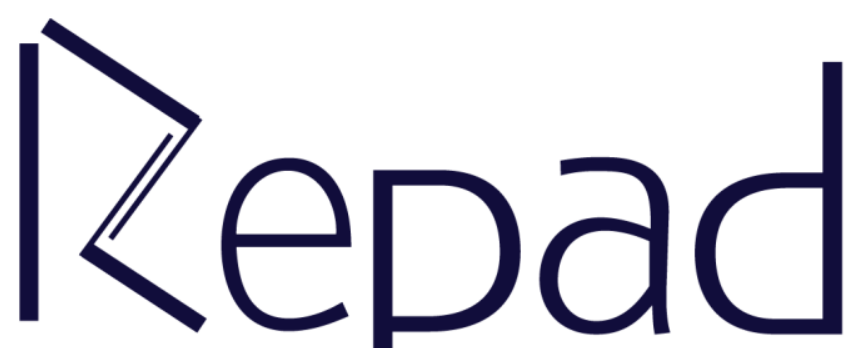

v. 5, n. 2, Maio-Agosto/2021

Revista Estudos e

Pesquisas em Administração 


\title{
ESTÁGIOS DE CRESCIMENTO: Um estudo em empresas do setor financeiro na região oeste do Paraná
}

\author{
Roberto Francisco de Souza \\ robertofsouzajr@gmail.com \\ https://orcid.org/0000-0001-9776-9139 \\ http://lattes.cnpq.br/7229026673672315 \\ Universidade Estadual do Oeste do Paraná \\ Salvador, Bahia, Brasil \\ Delci Grapegia Dal Vesco \\ delcigrape@gmail.com \\ https://orcid.org/0000-0002-0818-3142 \\ http://lattes.cnpq.br/3321706750568197 \\ Universidade Estadual do Oeste do Paraná \\ Cascavel, Paraná, Brasil \\ Adhmir Renan Voltolini Gomes \\ adhmir.renan@gmail.com \\ https://orcid.org/0000-0003-2089-5924 \\ http://lattes.cnpq.br/4313589612542355 \\ Fundação Universidade Regional de Blumenau \\ Blumenau, Santa Catarina, Brasil
}

\section{Resumo}

O estudo teve por objetivo analisar qual a fase de crescimento das cooperativas de crédito e os bancos públicos e bancos privados situados na região oeste do Paraná. A metodologia utilizada caracteriza-se como descritiva, realizada por meio de levantamento ou survey, com abordagem quantitativa do problema e análise de dados por meio do Teste Tukey e ANOVA. O universo de pesquisa contemplou 238 respondentes, sendo 80 de bancos públicos, 63 de bancos privados e 95 de cooperativas de crédito, empresas pertencentes à base territorial do Sindicato dos Bancários sediada em Cascavel, PR, com amostra não probabilística e por conveniência, compreendendo o período de maio a junho de 2017. O levantamento de dados foi realizado pela aplicação de questionário direcionado aos gerentes e funcionários com poder decisão nas empresas objeto de estudo. Os resultados mostram que os bancos públicos e privados possuem características do quarto estágios de crescimento. Embora a média das respostas indique uma fase de transição entre o terceiro estágio. No entanto, as cooperativas diferem dos demais bancos (públicos e privados), uma vez que apresentam caraterísticas do terceiro estágio, pois possuem altas taxas de crescimento, tanto nas vendas quanto no número de funcionários, a estrutura interna e a comunicação estão se tornando mais formais, e cada vez mais indivíduos estão assumindo papéis especializados.

Palavras-chave: Crescimento Interno; Estágios de Crescimento; Controle Gerencial 


\title{
GROWTH STAGES: A study in financial sector companies in the western region of Parana
}

\begin{abstract}
This study aimed to verify in which classify companies once the growth stage of the companies under study, differ from each other. The methodology used is characterized as descriptive, carried out through survey, with quantitative approach of the problem and data analysis through Tukey Test and ANOVA. The research universe included 238 respondents, 80 from public banks, 63 from private banks and 95 from credit unions, companies belonging to the territorial base of the Bankers Union based in Cascavel, PR, with a non-probabilistic and convenience sample, comprising the period from May to June 2017. The data collection was performed by applying a questionnaire directed to managers and employees with decision-making power in the companies under study. The results show that public and private banks have characteristics of the fourth stages of growth. Although the average of the responses indicates a transition phase between the third stage. However, cooperatives differ from other banks (public and private) in that they have third-stage characteristics, as they have high growth rates in both sales and headcount, internal structure and communication are becoming more and more individuals are taking on specialized roles.
\end{abstract}

Keywords: Internal Growth; Growth stages; Management control

Submetido: $25 / 02 / 2021$

Revisões Requeridas: 03/04/2021

Aceito: $24 / 07 / 2021$

Publicado: 31/08/2021

\section{INTRODUÇÃO}

O crescimento das empresas desperta atenção e atrai interesse de acadêmicos, executivos e políticos. $\mathrm{O}$ primeiro procura entender o crescimento das firmas e como ocorre esse processo testando as teorias existentes em setores industriais de países distintos, o empresário utiliza as informações geradas na academia para compreender os cenários e as variáveis que envolvem o crescimento da firma afim de encontrar alternativas que induzam ao crescimento empresarial no cenário ao qual estão inseridos, por fim os políticos, que são os responsáveis pela criação de políticas públicas para impulsionar o crescimento e desenvolvimento do país, dessa maneira a pesquisa apresenta contribuição social.

Penrose (1959) desenvolveu a Teoria do Crescimento da Firma redefinindo a firma como "um conjunto único de recursos produtivos, cujas disponibilidades e diferentes possibilidades de combinação irão determinar o seu potencial de expansão", expondo que existiam diferenciais importantes em cada empresa que lhes emprestavam condições diferenciadas de desempenho.

Segundo Penrose (2006), os limites de crescimento da firma estariam condicionados a uma competência empresarial, no sentido do empresário, de conseguir imaginar alternativas de negócios e de recombinar os recursos produtivos disponíveis, o crescimento rentável de uma empresa poderá ser ampliado ou limitado em função do gerenciamento de seus recursos, especialmente os recursos internos, tendo como aspecto 
fundamental o trabalho em conjunto dos recursos humanos (colaboradores e gerente), a experiência e o conhecimento dos envolvidos.

A autora destaca os serviços gerenciais ou capacidades organizacionais da firma como o principal responsável pelo seu crescimento; no segundo plano estão os fatores estruturais que são comuns às firmas de um mesmo setor, sendo que o argumento de sua teoria era o fornecimento de serviços gerenciais à empresa.

Penrose (2006) argumenta que a taxa de crescimento de uma firma é limitada pelo aumento dos conhecimentos nela existentes, mas que o tamanho de uma firma pode continuar a crescer, por força de sua eficiência administrativa, até alcançar suas fronteiras de expansão. Com a ênfase de Penrose a esses recursos internos, a literatura sobre crescimento oferece suporte aos argumentos da autora, ajudando a explicar o crescimento da firma.

No cenário internacional diversos pesquisadores como Porter (1980), Williamson (1985), Barney (1991), Chandler (1997), Geroski (1995; 1998) e Zhou (2009), deram sequência a Teoria de Crescimento da Firma, agregando novos cenários e variáveis. No Brasil, Fleck, (2003), Junior e Ruiz (2008), Sauerbronn, Sauerbronn e Hansenclever (2011), têm estudado o crescimento das firmas, buscando, entre outros aspectos, destacar as condições necessárias à expansão e à sobrevivência destas ao longo do tempo. Dadas as pesquisas anteriores sobre o tema, observa-se que os estudos se concentram em investigar o crescimento, pouco se tem discutido como ocorre esse processo evolutivo das organizações. Diante do contexto tem-se a seguinte questão norteadora da pesquisa: Em qual fase de crescimento encontram-se as cooperativas de crédito e os bancos públicos e bancos privados situados na região oeste do Paraná?

Dado o contexto apresentado, este artigo tem por objetivo investigar se as empresas objeto de estudo (cooperativas de crédito e os bancos públicos e privados) apresentam diferentes estágios de crescimento, para tal formula-se a hipótese de pesquisa:

H1 - Os bancos públicos e privados apresentam características semelhantes, e encontram-se no mesmo estágio de crescimento; contudo, as cooperativas de crédito diferem desses e encontram-se em estágio diferente.

Assim a presente pesquisa justifica-se pela carência de investigações sobre o crescimento da firma, bem como as fases de crescimento. Ainda por discutir os fatores que conduzem as fases de crescimentos nas organizações do setor financeiro sob a perspectiva de funcionários e gerentes para ampliar o debate sobre a tomada de decisões estratégicas.

\section{FUNDAMENTAÇÃO TEÓRICA} crescimento.

Esta seção constitui-se de revisão da literatura sobre fases e estágios de

\section{Crescimento Interno}

Penrose (2006) argumenta que o crescimento interno não ocorre automaticamente e que o planejamento e a alocação de recursos para a expansão são necessários. A fim de poder aproveitar as oportunidades de crescimento no mercado, 
recursos especializados e a capacidade gerencial precisam estar disponíveis para a empresa. Durante o processo de ampliação, novos serviços gerenciais precisam ser criados e uma melhoria geral em habilidades e eficiência ocorre. Ao longo do tempo, os gestores acumulam experiência, demonstrada pelos seus conhecimentos adquiridos e pela maior capacidade de utilizar esse conhecimento, levando a uma base de recursos versátil em termos da gama de serviços que eles podem oferecer.

A autora discute o crescimento interno da firma em função de dois pressupostos: $\mathrm{O}$ primeiro de que a oferta de recursos (materiais e imateriais) à firma não se apresenta limitada, sendo passível de ser obtida a um determinado preço; e o segundo de que sempre existem oportunidades disponíveis em algum segmento de mercado. Por meio de um estudo detalhado, utilizando o histórico de empresas privadas, ela fornece uma análise para além das empresas em um contexto específico. Ela manteve seu foco em processos internos de mudança, enfatizando a importância do posicionamento da empresa no ambiente industrial. Para a autora, o empreendedorismo é um ingrediente chave de sua teoria, pois compreende o julgamento empresarial necessário para reconhecer oportunidades de mercado. O crescimento das empresas é impulsionado por uma "oportunidade produtiva", em um processo cumulativo, endógeno e de interação entre a base produtiva da empresa e oportunidades de mercado, que se refletem, respectivamente, nas capacidades organizacionais da firma.

Segundo Penrose (2006), a visão da firma fundamentalmente dinâmica sustenta que o crescimento é conduzido por um impulso interno gerado por se aprender fazendo. Os gestores se tornam mais produtivos ao longo do tempo, acostumando-se às tarefas e funções executivas a que, inicialmente, colocavam restrições por causa de problemas antes não percebidos, porém logo se tornariam familiares e rotineiros. Os gestores ganharam experiência, portanto. Suas tarefas administrativas exigiam menos atenção e menos energia. Como resultado, recursos gerenciais continuamente estão sendo liberados. Esse excesso de talento gerencial pode ser usado para se concentrar nas oportunidades de crescimento e de criação de valor (em especial, a formação de novos gestores). As empresas são confrontadas com fortes incentivos para crescer, porque enquanto "o conhecimento possuído por pessoal de uma firma tende a aumentar automaticamente com a experiência", há um desafio para tirar o máximo proveito do valioso conhecimento específico da firma (PENROSE, 2006).

Bahadir, Bharadwaj e Parzen (2009), evidenciam as variáveis endógenas (internas) que influenciam o crescimento das empresas, sendo; (i) inovação, (ii) orientação de marketing, (iii) publicidade, (iv) redes interorganizacionais, (v) orientação empresarial, (vi) capacidade de gestão, (vii) idade firma, (viii) tamanho da empresa, (ix) competição, (x) munificência, e (xi) dinamismo. No entanto as variáveis que estão sob o controle de um gerente são: inovação, publicidade, orientação de mercado, redes interorganizacionais, orientação empresarial e capacidade gerencial, e servem como impulsionadores positivos do crescimento interno (BAHADIR; BHARADWAJ; PARZEN, 2009).

Nesse sentido, cabe ao gestor utilizar a experiência e o conhecimento disponíveis, proporcionando assim um incentivo para o crescimento, a partir da otimização dos recursos internos ou por meio de fusões e aquisição (PENROSE, 2006).

$\mathrm{O}$ crescimento por meio de fusões e aquisições são mecanismos de crescimento externo da firma, tópico discutido a seguir. 


\section{Crescimento Externo}

O crescimento externo da firma é um mecanismo advindo do mercado, que pode se dar por meio de aquisições, fusões, incorporações de outras empresas ou até mesmo de unidades de negócios ou parques fabris.

Penrose (2006) também fornece argumentos diferentes para explicar porque as empresas podem optar por adquirir empresas existentes. Os custos, bem como dificuldades de gestão e técnicas de entrar em um novo campo poderiam ser reduzidos por assumir outra empresa. Pode ser mais barato assumir uma unidade de produção existente do que construí-la a partir do zero. A aquisição de outra empresa também pode ser orientada por qualificações específicas do alvo de aquisição. A aquisição pode ser utilizada como meio para obter os serviços produtivos e os conhecimentos necessários para estabelecer-se num novo campo e esse acréscimo de novos serviços administrativos e técnicos aos serviços produtivos que a firma já detém assume muitas vezes maior importância do que a eliminação de um concorrente ou a redução dos custos de ingresso. Assim, as aquisições frequentemente constituem um meio bastante adequado para tomar conhecimento das técnicas e dos problemas de um novo campo quando uma quer decidir se a expansão, no referido campo, representa ou não uma utilização correta para seus próprios recursos.

No entanto, os motivos para as aquisições têm sido discutidos, principalmente, para o contexto de grandes empresas (ANGWIN, 2007; TRAUTWEIN, 1990), e incluem um aumento no poder de gestão e outras ambições pessoais por parte dos gestores de topo, aumento da quota de mercado, redução de custos, aumento da credibilidade financeira, aumento do valor de empresas de baixo desempenho ou subvalorizadas, concorrência ou sobre a capacidade numa indústria, reduzindo a ameaça de ter a própria empresa assumida, bem como falta de imaginação de outros modos de crescimento do que aquisição.

Para as pequenas e médias empresas (PMEs), a expansão por meio da aquisição é restringida pela base de recursos da empresa (Penrose, 2006). Consequentemente, na literatura sobre fusões e aquisições, as PMEs são mais frequentemente discutidas como objetivos de aquisição do que como adquirentes. Por exemplo, Rogers et al. (2007) considerou que as PMEs ativas em matéria de propriedade intelectual (em termos de patentes e marcas) eram mais suscetíveis de estarem envolvidas em atividades de fusões e aquisições do que as PMEs não ativas no domínio da propriedade intelectual. Hussinger (2010) investigou que a tecnologia pode ser especialmente importante para a decisão de adquirir uma empresa menor.

Por fim, mesmo o crescimento externo pressupõe a existência de certos tipos de qualidades empresariais internas da firma, e a integração bem-sucedida das firmas adquirentes e adquiridas numa única nova, no sentido usado nesse estudo, requer serviços administrativos da firma adquirente (PENROSE, 2006).

\section{Mensuração do Crescimento}

O crescimento é visto por Zhou (2009) como um resultado da combinação dos recursos, capacidades e rotinas. No entanto para medir o crescimento das organizações vários autores contribuem com a temática propondo métricas, ou modelos de mensuração do crescimento. Kimberly (1976), evidencia as métricas de mensuração de crescimento mais utilizadas, como sendo as vendas (ou receitas), número de funcionários e total de ativos. 
De acordo com Penrose (2006), o tamanho da empresa deve ser medido em relação ao valor presente do total de seus recursos (incluindo seu pessoal), usado para seus próprios propósitos produtivos. Isso é quase impossível de se descobrir na prática e, na ausência de qualquer medida realmente satisfatória de tamanho, tem-se uma ampla escolha a depender do propósito do gerente. As técnicas de mensuração de crescimento das firmas são exclusivas de cada empresa; não podem ser "redutíveis a qualquer denominador comum e são, portanto, incapazes de tratamento quantitativo". Ela indica algumas métricas de mensuração do crescimento das empresas: tamanho, ativo fixo, número de funcionários e vendas - embora ressalte que, devido à natureza das informações contábeis, não há meios para medir o tamanho e crescimento com precisão e isento de objeções conceituais.

Geroski (1995) indicou, em seu estudo, algumas métricas que podem ser utilizadas para medir o crescimento das firmas: o valor financeiro ou de mercado de ações, o número de funcionários, as vendas e receitas, a capacidade produtiva, o valor da produção e o valor acrescentado da produção. Garnsey, Stam e Heffernan (2006), em consonância com Geroski (1995), afirmam que, para examinar os caminhos de crescimento da firma, são necessárias métricas, tais como os insumos, o valor da empresa e as saídas. Os autores explicam que cada uma dessas medidas, ilustram algumas características do crescimento da firma e estão sujeitas a limitações, como o indicador de crescimento.

Para Garnsey, Stam e Heffernan (2006), o crescimento de uma empresa pode ser medido em termos de insumos, tais como fundos de investimento e funcionários (em termos de valor da empresa), ativos, capitalização de mercado, valor econômico adicionado, ou saídas (receitas de vendas, lucros). Para os autores, o número de funcionários é a medida mais comumente utilizada, porque oferece dados comparáveis e padronizados sobre a taxa e a direção em que uma empresa vem se expandindo. As vendas (volume de negócios) devem ser ajustadas pela inflação e são afetadas pela integração vertical (o quanto das vendas finais são produzidas internamente ou compradas).

A avaliação dos ativos da empresa é um indicador composto de crescimento. Isso inclui bens tangíveis, como equipamentos produtivos e edifícios, e uma avaliação de ativos intangíveis, a perícia da empresa e a reputação. A avaliação da empresa varia com o sentimento do investidor ao longo do ciclo de negócios. Uma bateria de índices financeiros é fornecida aos investidores, uma vez que as empresas se tornem públicas (GARNSEY; STAM; HEFFERNAN, 2006).

Whetten (1987) observa que o tamanho é uma medida absoluta, enquanto o crescimento é definido como uma medida relativa de tamanho ao longo do tempo. Portanto, discussões sobre conceitos de tamanho organizacional são valiosas ao procurar identificar conceitos apropriados de crescimento organizacional. Estudos que medem a organização e o crescimento foi foram criticados por se concentrarem em uma única dimensão de mudança de tamanho, em vez de usar múltiplas dimensões (BIRLEY; WESTHEAD, 1990).

Kimberly (1976) identifica várias medidas de tamanho utilizadas na literatura, incluindo funcionários, ativos, capacidade e vendas. Embora essas medidas possam ser correlacionadas empiricamente, elas diferem conceitualmente. Por exemplo, o número de funcionários que trabalha em um conjunto de organizações pode não exibir o mesmo padrão de mudança em relação ao tempo como o volume de vendas dessas organizações, devido às melhorias na eficiência do processo. 
Em Janssen (2003), o crescimento é um fenômeno complexo e multidimensional e uma abordagem puramente interna (limitada ao impacto dos recursos e aos fatores ligados ao gerente), negligencia o potencial de previsão das variáveis ligadas à empresa, a estratégia, o meio ambiente e as interações entre essas variáveis. No entanto Kimberly (1976) alega que o tamanho da organização não pode ser medido simplesmente considerando-se as vendas. Múltiplas métricas devem ser consideradas para medir o crescimento. Por isso, nesta pesquisa, optou-se por analisar os fatores internos de crescimento das empresas relacionados aos funcionários e gerentes.

Zhou (2009) descreve os determinantes do crescimento da firma frequentemente debatidos na literatura: idade e tamanho da firma, estratégias da firma (tais como mercado orientação e orientação empreendedora), recursos internos da firma (incluindo, humanos, capital, e recursos financeiros), e a estrutura organizacional e a capacidade dinâmica.

\section{Fases do Crescimento da Firma}

A criação e o crescimento das organizações continuam a ser um tema de interesse de pesquisa (KIMBERLY; MILES 1980; QUINN; CAMERON, 1983). Nessa literatura, um conceito amplamente empregado, mas ainda controverso, é o de estágios de crescimento no ciclo de vida da organização. De acordo com Lima et al. (2015), os estágios de ciclo de vida de uma firma podem exercer efeitos significativos sobre os aspectos mercadológicos, estratégias de investimentos e financiamentos em cada fase de vida da empresa. Foram propostos modelos de vários estágios que assumem que existem padrões previsíveis no crescimento das organizações e que esses padrões se desenvolvem com períodos de tempo discreto, ou seja, considerados como estágios (SMITH; MITCHELL; SUMMMER, 1985).

Para Kazanjian e Drazin (1989), estes modelos possuem diferentes características distintivas. Por exemplo, Scott (1970) argumentou que os estágios são impulsionados pela busca de novas oportunidades de crescimento, enquanto Greiner (1972) vê os estágios como uma resposta às crises internas. Alguns modelos sugerem que as empresas progridem por etapas de forma sequencial, enquanto outras argumentam que podem haver vários caminhos através dos estágios (ADIZES, 1979).

A maioria dos modelos ignora os fatores que levaram à criação formal da empresa. Van de Ven, Hudson Schroeder (1984) fornecem uma explicação explícita sobre como e por que a empresa foi formada. Finalmente, os modelos diferem em termos de número de estágios. Vários exemplos podem ser encontrados em modelos de três estágios Moore (1959), Cooper (1979), Smith, Mitchell e Summer (1985), os modelos de quatro estágios de Rhenman (1973), e Quinn e Cameron (1983), e modelos de cinco, e mais etapas (ADIZES, 1979; MILLER; FRIESEN, 1984; VAN DE VEN; HUDSON; SCHROEDER, 1984).

Para Greiner (1972), as empresas evoluem ao longo de cinco fases, conforme representadas na Figura 1. Cada fase é caracterizada por um período de crescimento relativamente estável. Essas fases estão identificadas com a natureza e a característica dos problemas de gestão de cada uma: criatividade, direção, delegação, coordenação e colaboração. Também são separadas por quatro crises: de liderança, autonomia, controle e burocracia.

Conforme Greiner (1972), a primeira fase é a da criatividade, com as características do período da evolução criativa: os fundadores da empresa são tecnicamente ou empreendedoramente orientados. Normalmente, eles desprezam as 
atividades de gestão. Suas energias mentais e físicas são absorvidas inteiramente na fabricação e na venda de um novo produto.

Figura 1 - Modelo de Fases de Crescimento de Greiner

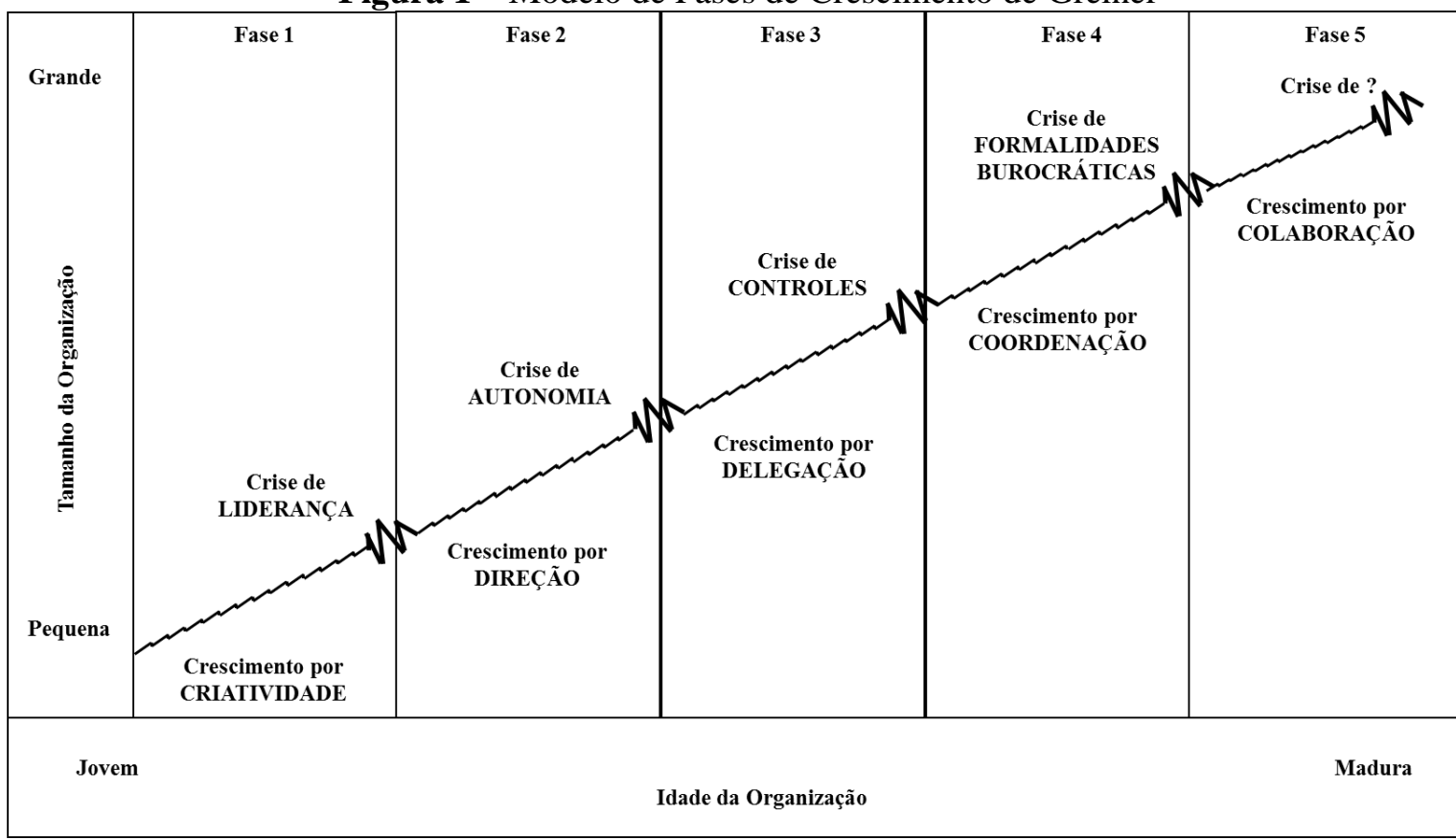

Fonte. Greiner (1972)

A comunicação entre funcionários é casual. As longas horas de trabalho são recompensadas com salários modestos e com a promessa de benefícios de propriedade. O controle de atividades vem a partir do feedback do mercado imediato. A gestão funciona como os clientes reagem a essas atividades (GREINER, 1972).

Na segunda fase, o crescimento é constituído pela direção (gestão). Nela, as empresas sobrevivem à primeira fase, por meio da nomeação de um gerente de negócios, capaz de embarcar em um período de crescimento sustentado, geralmente sob a liderança confiável e diretiva. A estrutura organizacional funcional está em processo para separar a fabricação de atividades de marketing. As atribuições de trabalho se tornam mais especializadas, sistemas de controle são inseridos e a comunicação torna-se mais formal e impessoal, com o uma hierarquia de títulos e posições construídas (GREINER, 1972).

A próxima fase é a da delegação. O crescimento evolui a partir da aplicação bem sucedida de uma estrutura organizacional descentralizada. Essa fase possui as seguintes características: mais responsabilidades são dadas aos gerentes de plantas e territórios de mercado. Os centros de lucro e bônus são usados para estimular a motivação. Os principais executivos na sede restringem-se ao gerenciamento por exceção, com base em relatórios periódicos de campo. $\mathrm{O}$ gerenciamento concentra-se muitas vezes em decisões voltada ao crescimento das organizações (GREINER, 1972).

Greiner (1972) descreve a quarta fase como sendo a fase da coordenação. O período evolutivo é caracterizado pelo uso dos sistemas formais utilizados para conseguir uma maior coordenação e pelos altos executivos assumirem a responsabilidade para a iniciação e a administração desses novos sistemas. Ou seja, nessa fase, ocorre a descentralização. Os procedimentos de planejamento formal são 
estabelecidos e intensivamente analisados. Certas funções técnicas, como processamento de dados, são centralizadas na sede, enquanto as decisões operacionais diárias ocorrem nas filiais.

Por fim, a fase da colaboração enfatiza uma forte colaboração interpessoal em uma tentativa de superar a crise da burocracia. Destacam-se a maior espontaneidade na ação de gestão, por intermédio de equipes, o confronto hábil de diferenças interpessoais, o controle social e a autodisciplina em assumir o lugar do controle formal (GREINER, 1972).

Para Kazanjian e Drazin (1989), o conceito de estágios de crescimento não é de forma alguma universalmente compartilhado: os trabalhos empíricos sobre o estágio de crescimento que emergiu nos últimos anos pouco têm feito para abordar este argumento fundamental. A maioria das pesquisas baseadas em dados sobre o crescimento organizacional simplesmente assumem a priori a existência de estágios, mas não testam explicitamente a progressão das empresas em estágios de crescimento ao longo do tempo.

\section{PROCEDIMENTOS METODOLÓGICOS}

Neste capítulo apresentam-se os procedimentos metodológicos adotados na condução da pesquisa.

\section{Delineamento da Pesquisa}

A pesquisa foi delineada conforme a tipologia de Sampieri, Collado e Lucio (2006): quanto ao problema de pesquisa, é quantitativa; aos objetivos, descritiva; aos procedimentos, é de levantamento ou survey.

A parte descritiva foi embasada em um levantamento ou pesquisa do tipo survey. Tripodi, Fellers e Meyer (1981), destacam que "pesquisas que procuram descrever com exatidão algumas características de populações designadas são tipicamente representadas por estudos de survey". De acordo com Gil (2002), a pesquisa descritiva procura descrever as características de determinada população ou fenômeno e as relações existentes entre suas variáveis. Uma das características mais expressivas da pesquisa descritiva está na utilização de técnicas padronizadas de coleta de dados.

A metodologia escolhida possui característica de estudo empírico analítico, realizado por meio de coleta e análise dos dados. Conforme Hair Jr. et al. (2010), ao utilizar da abordagem quantitativa em procedimentos descritivos, nos quais se procura descobrir e classificar a relação entre variáveis, busca-se a validação de fatos, o encontro de estimativas e relacionamentos e a testagem de hipóteses.

Os participantes envolvidos na análise foram selecionados intencionalmente e por acessibilidade, conforme sugere Creswell (2010). Justifica-se a utilização dessa metodologia pela dificuldade de acesso a todas as agências dos bancos e cooperativas de crédito pertencentes à base territorial de Cascavel, seja pela dificuldade de acesso e aceitabilidade por parte das empresas e dos funcionários para participar do estudo, ou pela dificuldade nos contatos. A intencionalidade também se justifica pelo critério de questionar apenas gerentes, líderes, encarregados, supervisores e demais funcionários com poder decisão das empresas objeto de estudo, a fim de investigar os estágios de crescimento. 


\section{Constructo da Pesquisa e Modelo de Análise}

Dessa forma, estruturou-se o constructo da pesquisa, a fim de apresentar os objetivos específicos, relacionando-os às variáveis, às sub variáveis, à operacionalização e às medidas utilizadas, vide Quadro 1.

Quadro 1. Constructo referente aos Estágios de Crescimento

\begin{tabular}{|c|c|c|c|}
\hline Objetivo & Autor & Hipótese & Método \\
\hline $\begin{array}{l}\text { a) Classificar se o } \\
\text { estágio de } \\
\text { crescimento das } \\
\text { empresas objeto de } \\
\text { estudo, diferem } \\
\text { entre si; }\end{array}$ & $\begin{array}{l}\text { Greiner (1972) } \\
\text { Najmaei (2014) }\end{array}$ & H1 & $\begin{array}{c}\text { Estatística } \\
\text { Descritiva } \\
\text { Teste Tukey } \\
\text { ANOVA }\end{array}$ \\
\hline \multicolumn{4}{|c|}{ Estágios/Afirmação } \\
\hline 1 & 2 & 3 & 4 \\
\hline $\begin{array}{l}\text { Dentro desta } \\
\text { empresa, a maioria } \\
\text { dos nossos } \\
\text { funcionários tem } \\
\text { tarefas técnicas, são } \\
\text { considerados mais } \\
\text { generalistas do que } \\
\text { especialistas, pois } \\
\text { todos nós } \\
\text { executamos várias } \\
\text { tarefas. Nós nos } \\
\text { assemelhamos mais } \\
\text { a um grupo de } \\
\text { tarefas do que a } \\
\text { uma organização. } \\
\text { Formalidade e } \\
\text { procedimentos são } \\
\text { quase inexistentes } \\
\text { nesta empresa, mas } \\
\text { o presidente / } \\
\text { empresário é central } \\
\text { para todas as } \\
\text { funções e } \\
\text { comunicações. O } \\
\text { foco principal de } \\
\text { nossas atividades é } \\
\text { o desenvolvimento } \\
\text { de produtos e } \\
\text { serviços }\end{array}$ & $\begin{array}{l}\text { Dentro desta empresa, } \\
\text { a maioria dos nossos } \\
\text { funcionários tem } \\
\text { tarefas técnicas, são } \\
\text { considerados mais } \\
\text { generalistas do que } \\
\text { especialistas, pois } \\
\text { todos nós executamos } \\
\text { várias tarefas. Nós nos } \\
\text { assemelhamos mais a } \\
\text { um grupo de Dentro } \\
\text { desta empresa, a } \\
\text { maioria dos nossos } \\
\text { funcionários tem } \\
\text { tarefas técnicas, são } \\
\text { considerados mais } \\
\text { generalistas do que } \\
\text { especialistas, pois } \\
\text { todos nós executamos } \\
\text { várias tarefas. Nós nos } \\
\text { assemelhamos mais a } \\
\text { um grupo de }\end{array}$ & $\begin{array}{l}\text { A empresa é } \\
\text { caracterizada por altas } \\
\text { taxas de crescimento, } \\
\text { tanto nas } \\
\text { vendas/receitas quanto } \\
\text { no número de } \\
\text { funcionários. O foco } \\
\text { interno principal é em } \\
\text { torno de questões de } \\
\text { como produzir, vender } \\
\text { e distribuir os } \\
\text { produtos/serviços em } \\
\text { volume com o objetivo } \\
\text { de atingir rentabilidade. } \\
\text { A estrutura interna e a } \\
\text { comunicação estão se } \\
\text { tornando mais formais } \\
\text { e cada vez mais } \\
\text { indivíduos } \\
\text { assumindo estão } \\
\text { especializados. papéis }\end{array}$ & $\begin{array}{l}\text { Dentro desta empresa, as } \\
\text { principais atividades } \\
\text { internas incluem: (1) } \\
\text { comercializar produtos } \\
\text { financeiros voltados para o } \\
\text { setor financeiro e / ou } \\
\text { linhas de produtos } \\
\text { totalmente novos; (2) } \\
\text { assegurar o financiamento } \\
\text { do crescimento; (3) } \\
\text { assegurar ou aumentar a } \\
\text { quota de mercado; (4) } \\
\text { penetrar novos territórios } \\
\text { geográficos. A empresa } \\
\text { tem uma formalidade de } \\
\text { estrutura organizacional, } \\
\text { regras e procedimentos. } \\
\text { Orçamento e planejamento } \\
\text { estratégico são processos } \\
\text { estabelecidos. Uma equipe } \\
\text { de alta gerência composta } \\
\text { por alguns indivíduos com } \\
\text { ampla experiência no } \\
\text { seguimento está no local } \\
\text { ou está sendo contratado. }\end{array}$ \\
\hline
\end{tabular}

Fonte. Adaptado de Penrose (2006) e Najmaei (2014) 


\section{Classificação, Hipóteses e Equações}

O modelo de ANOVA utilizado classifica-se como Delineamento Inteiramente Casualizado (DIC), vide Quadro 2.

Quadro 2. Análise Preliminar ANOVA

\begin{tabular}{|l|c|c|c|c|c|c|}
\hline \multicolumn{1}{|c|}{ Análise } & Modelo A & Modelo B & $\begin{array}{c}\text { Modelo } \\
\text { C }\end{array}$ & $\begin{array}{c}\text { Modelo } \\
\text { D }\end{array}$ & Modelo D & $\begin{array}{c}\text { Modelo } \\
\text { D }\end{array}$ \\
\hline $\begin{array}{c}\text { Unidade } \\
\text { Experimental }\end{array}$ & $\begin{array}{c}\text { Percepção } \\
\text { sobre o } \\
\text { Estágio de } \\
\text { Crescimento }\end{array}$ & Gênero & $\begin{array}{c}\text { Tempo } \\
\text { de } \\
\text { empresa }\end{array}$ & $\begin{array}{c}\text { Tempo } \\
\text { de cargo }\end{array}$ & Escolaridade & Faixa \\
\hline $\begin{array}{l}\text { Variável de } \\
\text { Interesse }\end{array}$ & \multicolumn{2}{|c|}{ Percepção de crescimento da firma dos colaboradores de Bancos Públicos, } \\
\hline $\begin{array}{l}\text { Fatores em } \\
\text { estudo }\end{array}$ & \multicolumn{4}{|c|}{ Privados e Cooperativas de Créditos. } \\
\hline $\begin{array}{l}\text { Níveis dos } \\
\text { fatores }\end{array}$ & \multicolumn{4}{|c|}{ Instituições Financeiras } \\
\hline Fatores & \multicolumn{5}{|c|}{ Fatores fixos (atribuídos de acordo com a classificação das instituições } \\
pesquisadas)
\end{tabular}

Fonte. Elaboração Própria

E as hipóteses propostas são:

$$
\begin{gathered}
H_{0}: \text { Públicas } s_{i}=\text { Privadas }_{i}=\text { Cooperativas }_{i}=\sigma^{2}=0 \\
H_{1}: \text { Para ao menos um dos fatores estudados a } \sigma^{2} \neq 0
\end{gathered}
$$

A hipótese nula descreve que a variância da percepção de crescimento da firma para todos os fatores estudados é estatisticamente igual à zero. Dessa forma, a Equação (X) descreve os modelos das ANOVA's propostos.

$$
U E_{i j}=\mu_{i}+T_{i}+\varepsilon_{i j}
$$

Onde,

$U E_{i j}$ Refere-se à percepção de crescimento da firma acordo com as unidades experimentais

$\mu_{i}$ Refere-se à média amostra de cada nível dos fatores;

$T_{i}$ Refere-se aos fatores estudados $=$ Pública $_{i}+$ Privada $_{i}+$ Cooperativa $_{i}$

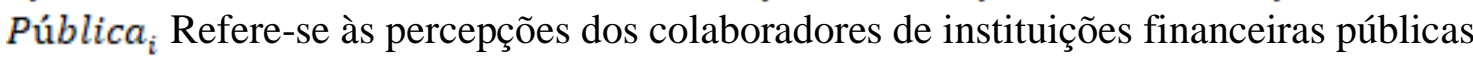
Privada $_{i}$ Refere-se às percepções dos colaboradores de instituições financeiras privadas

Cooperativa $_{i}$ Refere-se às percepções dos colaboradores de cooperativas de créditos $\varepsilon_{i j}$ Refere-se ao erro.

Foi realizado para comparação de média o teste de Tukey não balanceado. 


\section{RESULTADOS E DISCUSSÃO}

\section{Estatística descritiva, ANOVA e Teste Tukey}

Para caracterizar a amostra, um dos critérios utilizados nas pesquisas foi a estatística descritiva. Neste estudo, foi desenvolvida com o objetivo de compreender o comportamento dos dados. A estatística descritiva compreendeu: a) Medida de tendência central, a escolha foi a média; b) Medida de dispersão - o desvio padrão; c) Mínimos e Máximos.

Utilizou-se o teste e Análise de Variância (ANOVA), conforme Hair Jr. (2009), para verificar a significância dos fatores entre os grupos, estágios de crescimento, gênero, tempo na empresa, tempo no cargo, nível de escolaridade e idade.

O teste de Tukey caracteriza-se como um método que utiliza uma distribuição na mesma escala do teste t. O teste é utilizado quando se deseja comparar todos os pares de médias de populações, adotando-se um único nível de confiança. Ele consiste em calcular um valor tal acima do qual a diferença entre duas médias amostrais (em absoluto) é significativamente diferente de zero. $\mathrm{O}$ método de Tukey considera todas as possíveis diferenças dois-a-dois na amostra para um ordenamento destas.

\section{Estágios de Crescimento de Empresas}

Para identificar os estágios de crescimento em que se encontram os bancos e cooperativas de crédito utilizou-se os testes ANOVA e Tukey. Vide Tabela 1.

Tabela 1. Teste ANOVA

\begin{tabular}{|c|c|c|c|c|c|c|}
\hline \multicolumn{7}{|c|}{ ANOVA } \\
\hline & & $\begin{array}{l}\text { Soma dos } \\
\text { Quadrados }\end{array}$ & Df & $\begin{array}{c}\text { Quadrado } \\
\text { Médio }\end{array}$ & $\mathbf{F}$ & Sig. \\
\hline \multirow{3}{*}{ EC } & Entre Grupos & 13,063 & 2 & 6,532 & 10,237 & ,000 \\
\hline & Nos grupos & 149,933 & 235 & ,638 & & \\
\hline & Total & 162,996 & 237 & & & \\
\hline \multirow{3}{*}{ GEN } & Entre Grupos & ,302 & 2 & ,151 & 600 &, 549 \\
\hline & Nos grupos & 59,160 & 235 & ,252 & & \\
\hline & Total & 59,462 & 237 & & & \\
\hline \multirow{2}{*}{\multicolumn{2}{|c|}{$\begin{array}{l}\text { Entre Grupos } \\
\text { TEMPO Nos grupos }\end{array}$}} & 35,572 & 2 & 17,786 & 27,312 & ,000 \\
\hline & & 153,037 & 235 & ,651 & & \\
\hline \multicolumn{2}{|c|}{ Total } & 188,609 & 237 & & & \\
\hline \multirow{2}{*}{\multicolumn{2}{|c|}{$\begin{array}{c}\text { Entre Grupos } \\
\text { TCARGONos grupos }\end{array}$}} & 31,109 & 2 & 15,554 & 16,895 &, 000 \\
\hline & & 216,358 & 235 & ,921 & & \\
\hline & Total & 247,466 & 237 & & & \\
\hline \multicolumn{2}{|c|}{ ESCOLA_Entre Grupos } & 2,476 & 2 & 1,238 & 1,826 &, 163 \\
\hline \multirow{2}{*}{\multicolumn{2}{|c|}{ Nos grupos }} & 159,256 & 235 & ,678 & & \\
\hline & & \multicolumn{4}{|c|}{ Total } & \\
\hline \multirow{3}{*}{ FAIXA } & Entre Grupos & 28,446 & 2 & 14,223 & 18,742 & ,000 \\
\hline & Nos grupos & 178,332 & 235 & ,759 & & \\
\hline & Total & 206,777 & 237 & & & \\
\hline
\end{tabular}

Fonte. Elaboração Própria 
Conforme observado na Tabela 1, há diferença estatística na classificação e identificação das empresas nos estágios de crescimento, tempo de empresa, tempo de cargo, e idade, ou seja, existe diferença na composição do capital humano, dessas instituições. De acordo com o teste $\mathrm{F}$, foram encontradas evidências de diferenças significativas, ao nível de $1 \%$ de probabilidade, entre os tratamentos com relação a composição dos estágios de crescimento. Rejeitando, portanto, a hipótese de nulidade, ou seja, existe diferença entre média da percepção dos estágios de crescimento entre as instituições públicas, privadas e cooperativas de crédito.

Os Estágios de Crescimento, representam as etapas de crescimento bem como recursos necessários ao crescimento, ao mesmo tempo em que as empresas precisam lidar com as crises de cada fase do crescimento. Nesse estudo as Cooperativas apresentam características da primeira e da segunda fase de crescimento. Devido, a maioria dos funcionários realizarem tarefas técnicas, que são mais generalistas do que especialistas, assemelham mais a um grupo de tarefas do que a uma organização. As Formalidade e procedimentos são quase inexistentes nesta empresa, as decisões do presidente prevalecem todas as funções e comunicações. $\mathrm{O}$ foco principal das atividades é o desenvolvimento de produtos e serviços. Essas características podem ser justificadas pelo dinamismo das cooperativas em captar recursos de seus associados e oferecer produtos e serviços com preços abaixo dos praticado pelas instituições públicas e privadas, no entanto embora o sejam mais acessíveis, são oferecidos em menor escala que os demais.

As Instituições públicas e privadas diferentemente das cooperativas apresentam características da terceira e quarta fase de crescimento, possuindo altas taxas de crescimento, tanto nas vendas/receitas quanto no número de funcionários. O foco interno principal é em torno de questões de como produzir, vender e distribuir os produtos/serviços em volume com o objetivo de atingir rentabilidade. A estrutura interna e a comunicação estão se tornando mais formal e cada vez mais indivíduos estão assumindo papéis especializados, o que requer funcionários mais qualificados. Ao mesmo tempo em que apresentam excessos de controles e burocracia.

Destacam-se ainda na comercialização de produtos financeiros voltados para o setor financeiro e no desenvolvimento produtos totalmente novos de forma a assegurar o financiamento do crescimento e aumentar a quota de mercado além de penetrar novos territórios geográficos. Essas empresas possuem formalidade de estrutura organizacional, orçamento e planejamento estratégico estabelecidos, uma equipe de alta gerência composta por alguns indivíduos com ampla experiência no seguimento está no local ou está sendo contratado.

Quanto à variável gênero, os dados da pesquisa apontam maior concentração para o gênero feminino nas cooperativas de crédito, e masculino em instituições públicas e privadas. O tempo na empresa destaca a permanência dos colaboradores em instituições públicas, devido a forma de ingresso e plano de carreira. Em instituições privadas a média de permanência na empresa e no cargo é relativamente menor.

A variável escolaridade é expressiva em todas as instituições, no entanto funcionários com título de mestre foram identificados apenas em instituições públicas. Isso ocorre devido ao fato de existir flexibilidade por parte da instituição e do plano de carreira, o que não ocorre em empresas do setor privado. Já a faixa etária é composta por pessoas mais jovens na área privada, e pessoas com mais idade na área pública.

No entanto, para as variáveis gênero e nível de escolaridade, não foi estatisticamente significante, ou seja, essas variáveis são semelhantes nas empresas 
pesquisadas. As cooperativas crescem conforme as características apresentadas nas fases 1 e fase 2, crescimento por criatividade e por direção uma vez que são geridas por um grupo de pessoas (diretoria), enquanto apresenta crises de liderança e autonomia, colidindo com Greiner (1972). Diferentemente as instituições públicas e privadas apresentam características de crescimento das fases 3 e 4, o crescimento é influenciado pela deleção e coordenação, enquanto que, as crises são representadas pela quantidade de controles e burocracia. Esses resultados se assemelham complementam e justificam as fases de crescimento propostas por Greiner (1972).

Tabela 2. Teste Tukey

\begin{tabular}{lccc}
\hline & \multicolumn{2}{c}{ EC } \\
\hline Tukey HSD ${ }^{\mathrm{a}, \mathrm{b}}$ & \multicolumn{2}{c}{ Subconjunto para alfa $=0.05$} \\
\hline EMP & $\mathrm{N}$ & \multicolumn{2}{c}{2} \\
\cline { 2 - 4 } & & 3,011 & 3,413 \\
\hline Cooperativa & 95 & & 3,556 \\
\hline Instituições Públicas & 80 & &, 508 \\
\hline Instituições Privadas & 63 & 1,000 & \\
\hline Sig. & & &
\end{tabular}

Fonte: Elaboração Própria

Conforme indicado na Tabela 2, o teste Tukey, as cooperativas apresentam média de 3,011 pontos, ou seja, elas apresentam as características da terceira fase de crescimento a qual é caracterizada por altas taxas de crescimento, tanto nas vendas/receitas quanto no número de funcionários. $\mathrm{O}$ foco interno principal é em torno de questões de como produzir, vender e distribuir os produtos/serviços em volume com o objetivo de atingir rentabilidade. A estrutura interna e a comunicação estão se tornando mais formal e cada vez mais indivíduos estão assumindo papéis especializados.

Diferentemente, os bancos públicos apresentam médias de 3,413 pontos embora nesta pesquisa são três os bancos públicos pesquisados, dois federais e um estadual, á média apresentada indica uma área de transição entre a fase 3, caracterizada por altas taxas de crescimento, tanto nas vendas/receitas quanto no número de funcionários, para a fase 4 caracterizada por comercialização de produtos financeiros voltados para o setor financeiro e / ou linhas de produtos totalmente novos; (2) assegurar o financiamento do crescimento; (3) assegurar ou aumentar a quota de mercado; (4) penetrar novos territórios geográficos. No entanto se observados individualmente as instituições financeiras federais se enquadram no quarto estágio de crescimento.

Já os bancos privados apresentam média de 3,556, ou seja, essas instituições apresentam as características da quarta fase de crescimento, no qual as principais atividades internas incluem: (1) comercialização de produtos financeiros voltados para o setor financeiro e/ou linhas de produtos totalmente novos; (2) assegurar o financiamento do crescimento; (3) assegurar ou aumentar a quota de mercado; (4) penetrar novos territórios geográficos. A empresa tem uma formalidade de estrutura organizacional, regras e procedimentos. Orçamento e planejamento estratégico são processos estabelecidos. Uma equipe de alta gerência composta por alguns indivíduos com ampla experiência no seguimento está no local ou está sendo contratado. No entanto nesta 
pesquisa os estágios dois primeiros estágios não apresentam resultados estatisticamente significante.

Conforme demonstrado na Tabela 3 pelo teste de Tukey, ao nível de significância de 5\%, as médias dos estágios de crescimento de acordo com o, TEMPO tempo de empresa, TEMPO - tempo de cargo, e FAIXA - idade, apresentam diferenças significantes. As médias dos tratamentos das variáveis GEN - gênero e ESCOLA - nível de escolaridade não apresentam diferença estatisticamente significante, porém ressaltase esse efeito advém da homogeneidade dos dados dessas variáveis, que por sua vez, também não foram estatisticamente significante. Dessa forma atingiu-se o objetivo proposto na pesquisa de classificar se o estágio de crescimento das empresas objeto de estudo, diferem entre si.

Tabela 3. Teste Tukey Comparações Múltiplas

\begin{tabular}{cccc}
\hline Tukey HSD & \multicolumn{3}{c}{ Comparações múltiplas Diferença } \\
\cline { 2 - 4 } $\begin{array}{c}\text { Variável } \\
\text { Limite }\end{array}$ & Modelo & $\underline{\text { confianca 95\% dependente padrão }}$ & $\begin{array}{c}\text { Intervalo de } \\
\text { Limite }\end{array}$
\end{tabular}

(I) EMP (J) EMP média (I-Sig. J) inferior superior

\begin{tabular}{|c|c|c|c|c|c|c|c|}
\hline \multirow{6}{*}{ EC } & \multirow{2}{*}{ Cooperativa } & $\begin{array}{c}\text { Instituições } \\
\text { Privadas }\end{array}$ &,$- 5450^{*}$ & ,1298 &, 000 &,- 851 &,- 239 \\
\hline & & $\begin{array}{l}\text { Instituições } \\
\text { Públicas }\end{array}$ &,$- 4020^{*}$ &, 1212 &, 003 &,- 688 &,- 116 \\
\hline & \multirow[b]{2}{*}{$\begin{array}{l}\text { Instituições } \\
\text { Privadas }\end{array}$} & Cooperativa &, $5450^{*}$ & ,1298 & ,000 & 239 & ,851 \\
\hline & & $\begin{array}{c}\text { Instituições } \\
\text { Públicas }\end{array}$ &, 1431 & ,1345 &, 538 &,- 174 & ,460 \\
\hline & \multirow{2}{*}{$\begin{array}{l}\text { Instituições } \\
\text { Públicas }\end{array}$} & Cooperativa &, $4020^{*}$ &, 1212 &, 003 &, 116 & ,688 \\
\hline & & $\begin{array}{c}\text { Instituições } \\
\text { Privadas }\end{array}$ &,- 1431 & ,1345 &, 538 &,- 460 &, 174 \\
\hline \multirow{6}{*}{ GEN } & \multirow{2}{*}{ Cooperativa } & $\begin{array}{l}\text { Instituições } \\
\text { Privadas }\end{array}$ &,- 0079 & 0815 & ,995 &,- 200 &, 184 \\
\hline & & $\begin{array}{l}\text { Instituições } \\
\text { Públicas }\end{array}$ &,- 0783 & ,0761 &, 560 &,- 258 &, 101 \\
\hline & \multirow{2}{*}{$\begin{array}{c}\text { Instituições } \\
\text { Privadas }\end{array}$} & Cooperativa &, 0079 &, 0815 & ,995 &,- 184 & ,200 \\
\hline & & $\begin{array}{c}\text { Instituições } \\
\text { Públicas }\end{array}$ &,- 0704 & ,0845 & ,683 &,- 270 &, 129 \\
\hline & \multirow{2}{*}{$\begin{array}{l}\text { Instituições } \\
\text { Públicas }\end{array}$} & Cooperativa & ,0783 & ,0761 & 560 &,- 101 & ,258 \\
\hline & & $\begin{array}{c}\text { Instituições } \\
\text { Privadas }\end{array}$ &, 0704 & 0845 & ,683 &,- 129 &, 270 \\
\hline \multirow{3}{*}{ TEMPO } & \multirow{3}{*}{ Cooperativa } & $\begin{array}{l}\text { Instituições } \\
\text { Privadas }\end{array}$ &,$- 4914^{*}$ &, 1311 &, 001 &,- 801 &,- 182 \\
\hline & & $\begin{array}{l}\text { Instituições } \\
\text { Públicas }\end{array}$ &,$- 9013^{*}$ &, 1225 &, 000 & $-1,190$ &,- 612 \\
\hline & & Cooperativa &, $4914^{*}$ & ,1311 & ,001 &, 182 & ,801 \\
\hline
\end{tabular}




\begin{tabular}{|c|c|c|c|c|c|c|c|}
\hline & $\begin{array}{c}\text { Instituições } \\
\text { Privadas } \\
\end{array}$ & $\begin{array}{c}\text { Instituições } \\
\text { Públicas } \\
\end{array}$ &,$- 4099^{*}$ & 1359 & ,008 &,- 731 &,- 089 \\
\hline \multirow{6}{*}{ Variável } & \multicolumn{5}{|c|}{ Intervalo de Diferença } & \\
\hline & Modelo & \multicolumn{4}{|c|}{ confiança 95\% dependente padrão } & & \\
\hline & Sig. & J) inferior sur & erior & & & \multicolumn{2}{|c|}{ MP $\begin{array}{ll} & \text { Limite (I) } \\
(\mathbf{J}) \quad \mathbf{E M P}\end{array}$} \\
\hline & & Cooperativa &, $9013^{*}$ & , 1225 & ,000 & ,612 & 1,190 \\
\hline & Instituições & & & & & & \\
\hline & Públicas & $\begin{array}{l}\text { Instituições } \\
\text { Privadas }\end{array}$ & ,4099* &, 1359 & ,008 & ,089 &, 731 \\
\hline \multirow{6}{*}{ TCARGO } & \multirow{2}{*}{ Cooperativa } & $\begin{array}{l}\text { Instituições } \\
\text { Privadas }\end{array}$ &,$- 5051^{*}$ &, 1559 &, 004 &,- 873 &,- 137 \\
\hline & & $\begin{array}{l}\text { Instituições } \\
\text { Públicas }\end{array}$ &,$- 8368^{*}$ &, 1456 &, 000 & $-1,180$ &,- 493 \\
\hline & \multirow[b]{2}{*}{$\begin{array}{l}\text { Instituições } \\
\text { Privadas }\end{array}$} & Cooperativa &, $5051^{*}$ & ,1559 & 004 &, 137 & ,873 \\
\hline & & $\begin{array}{l}\text { Instituições } \\
\text { Públicas }\end{array}$ &,- 3317 &, 1616 &, 102 &,- 713 &, 049 \\
\hline & \multirow[b]{2}{*}{$\begin{array}{l}\text { Instituições } \\
\text { Públicas }\end{array}$} & Cooperativa & $8368^{*}$ & ,1456 & 000 & ,493 & 1,180 \\
\hline & & $\begin{array}{c}\overline{\text { Instituições }} \\
\text { Privadas }\end{array}$ &, 3317 &, 1616 &, 102 &,- 049 &, 713 \\
\hline \multirow{6}{*}{ ESCOLA } & \multirow[b]{2}{*}{ Cooperativa } & $\begin{array}{c}\text { Instituições } \\
\text { Privadas } \\
\end{array}$ &,- 0119 &, 1338 & ,996 &,- 327 &, 304 \\
\hline & & $\begin{array}{l}\text { Instituições } \\
\text { Públicas }\end{array}$ &,- 2204 &, 1249 &, 184 &,- 515 &, 074 \\
\hline & \multirow{2}{*}{$\begin{array}{l}\text { Instituições } \\
\text { Privadas }\end{array}$} & Cooperativa &, 0119 &, 1338 & ,996 &,- 304 & ,327 \\
\hline & & $\begin{array}{c}\text { Instituições } \\
\text { Públicas }\end{array}$ &,- 2085 &, 1387 & 291 &,- 536 &, 119 \\
\hline & \multirow[b]{2}{*}{$\begin{array}{l}\text { Instituições } \\
\text { Públicas }\end{array}$} & Cooperativa & ,2204 &, 1249 &, 184 &,- 074 &, 515 \\
\hline & & $\begin{array}{l}\text { Instituições } \\
\text { Privadas }\end{array}$ & ,2085 &, 1387 & ,291 &,- 119 &, 536 \\
\hline \multirow{6}{*}{ FAIXA } & \multirow{2}{*}{ Cooperativa } & $\begin{array}{c}\text { Instituições } \\
\text { Privadas } \\
\end{array}$ &,- 2834 &, 1415 &, 114 &,- 617 &, 050 \\
\hline & & $\begin{array}{l}\text { Instituições } \\
\text { Públicas }\end{array}$ &,$- 8046^{*}$ &, 1322 &, 000 & $-1,116$ &,- 493 \\
\hline & \multirow{2}{*}{$\begin{array}{c}\text { Instituições } \\
\text { Privadas }\end{array}$} & Cooperativa & ,2834 &, 1415 &, 114 &,- 050 & ,617 \\
\hline & & $\begin{array}{c}\text { Instituições } \\
\text { Públicas }\end{array}$ &,$- 5212^{*}$ &, 1467 &, 001 &,- 867 &,- 175 \\
\hline & Instituições & $\underline{\text { Cooperativa }}$ &, $8046^{*}$ &, 1322 &, 000 & ,493 & 1,116 \\
\hline & Públicas & $\begin{array}{l}\text { Instituições } \\
\text { Privadas }\end{array}$ &, $5212^{*}$ &, 1467 &, 001 &, 175 & ,867 \\
\hline
\end{tabular}

Fonte. Elaboração Própria. Nota. *A diferença média é significativa no nível 0.05 . 


\section{CONCLUSÃO}

No que concerne ao objetivo específico, classificar as empresas objeto de estudo nos estágios de crescimento. Os resultados mostraram que os bancos públicos e privados possuem características do quarto estágios de crescimento. Embora a média das respostas indique uma fase de transição entre o terceiro estágio, essas instituições apresentam altas taxas de crescimento, com foco e objetivo de atingir rentabilidade. A comunicação é formal e requer funcionários mais qualificados, mas apresentam excessos de controles e burocracia.

No entanto, as cooperativas diferem dos demais bancos (públicos e privados), uma vez que apresentam caraterísticas da segunda e da terceira fase de crescimento. A maioria dos funcionários realizam tarefas técnicas, as decisões do presidente e diretoria prevalecem em todas as funções e comunicações. O foco principal das atividades é o desenvolvimento de produtos e serviços. Essas características podem ser justificadas pelo dinamismo das cooperativas em captar recursos de seus associados e oferecer produtos e serviços com preços abaixo do praticado por outras instituições do mesmo seguimento, embora sejam mais acessíveis, são oferecidos em menor escala que os demais.

Dessa forma, a hipótese H1 foi aceita, ou seja, os bancos públicos e privados apresentam características semelhantes, e encontram-se no mesmo estágio de crescimento, contudo as cooperativas de crédito diferem desses e estão em estágio diferente. Para futuras pesquisas, sugere-se verificar a influência dos estágios de crescimento em seguimento distinto do setor financeiro, ou ainda investigar $o$ crescimento a partir de variáveis internas.

\section{REFERÊNCIAS}

ADIZES, I. Organizational passages-diagnosing and treating lifecycle problems of organizations. Organizational dynamics, v. 8, n. 1, p. 3-25, 1979.

ANGWIN, D. Motive archetypes in mergers and acquisitions (M\&A): the implications of a configurational approach to performance. In: Advances in mergers and acquisitions. Emerald Group Publishing Limited, 2007. p. 77-105.

BAHADIR, S. C.; BHARADWAJ, S.; PARZEN, M. A meta-analysis of the determinants of organic sales growth. International Journal of Research in Marketing, v. 26, n. 4, p. 263-275, 2009.

BARNEY, J. Firm resources and sustained competitive advantage. Journal of management. v.17, n. 1, p. 99-120, 1991

BIRLEY, S.; WESTHEAD, P. Growth and performance contrasts between 'types' of small firms. Strategic management journal, v. 11, n. 7, p. 535-557, 1990.

CHANDLER, A. D., "Strategy and Structure”, in Foss (org.), 1997.

COOPER, A. C. Strategy Management: New Venture and Small Business. In.: SCHENDEL, DE; HOFER, CW (ed.). Strategic Management. 1979. 
CRESWELL, J. W. Projeto de pesquisa métodos qualitativo, quantitativo e misto. In: Projeto de pesquisa métodos qualitativo, quantitativo e misto. 2010.

FLECK, D. L. Dois motores do crescimento corporativo. Revista de Administração de Empresas, v. 43, n. 4, p. 10-24, 2003.

GARNSEY, E.; STAM, E.; HEFFERNAN, P. New firm growth: Exploring processes and paths. Industry and Innovation, v. 13, n. 1, p. 1-20, 2006.

GEROSKI, P. A. What do we know about entry?. International Journal of Industrial Organization, v. 13, n. 4, p. 421-440, 1995.

GEROSKI, P. A. An applied econometrician's view of large company performance. Review of Industrial Organization, v. 13, n. 3, p. 271-294, 1998.

GIL, A. C. Como elaborar projetos de pesquisa. São Paulo, v. 5, n. 61, p. 16-17, 2002.

GREINER, L. E. Evolution and revolution as organizations grow. Harvard Business Review 50 (4): p. 37-46. 1972.

HAIR JR, J. F. et al. Modelagem de Equações Estruturais: uma introdução. Análise multivariada de dados, v. 6, 2009.

HAIR JR, J. F. et al. SEM: An introduction. Multivariate data analysis: A global perspective, p. 629-686, 2010.

HUSSINGER, K. On the importance of technological relatedness: SMEs versus large acquisition targets. Technovation, v. 30, n. 1, p. 57-64, 2010.

JANSSEN, F. Determinants of SME's Employment Growth Relating to the Characteristics of the Manager. Retrieved August, v. 16, p. 2006, 2003.

JÚNIOR, N. S.; RUIZ, R. M. Determinantes do desempenho das firmas a partir das novas capacitações internas: um estudo de firmas brasileiras. Revista de Economia Contemporânea, v. 12, p. 97-127, 2008.

KAZANJIAN, R. K.; DRAZIN, R. An empirical test of a stage of growth progression model. Management science, v. 35, n. 12, p. 1489-1503, 1989.

KIMBERLY, J. R. Organizational size and the structuralist perspective: A review, critique, and proposal. Administrative science quarterly, p. 571-597, 1976.

KIMBERLY, J. R.; KIMBERLY, J.; MILES, R. H. The organizational life cycle: Issues in the creation, transformation, and decline of organizations. Jossey-Bass Inc Pub, 1980. 
LIMA, A. S. de et al. Estágios do ciclo de vida e qualidade das informações contábeis no Brasil. Revista de Administração Contemporânea, v. 19, n. 3, p. 398-418, 2015.

MILLER, D.; FRIESEN, P. H. A longitudinal study of the corporate life cycle. Management science, v. 30, n. 10, p. 1161-1183, 1984.

MOORE, W., (Referenced in Starbuck, W., 1971. Organizational Growth and Development. London: Penguin Books), 1959.

NAJMAEI L., Arash et al. Leading growth: CEO's cognition, knowledge acquisition and business model innovation in face of dynamism. 2014.

PENROSE, E. The theory of growth of the firm. London: Basil Blackwell. 1959.

PENROSE, E. T. A teoria do crescimento da firma. Editora Unicamp, 2006.

PORTER, M. E.; STRATEGY, Competitive. Techniques for analyzing industries and competitors. Competitive Strategy. New York: Free, 1980.

QUINN, R. E.; CAMERON, K. Organizational life cycles and shifting criteria of effectiveness: Some preliminary evidence. Management science, v. 29, n. 1, p. 33-51, 1983.

RHENMAN, E. Organization theory for long-range planning. John Wiley \& Sons, 1973.

ROGERS, M., HELMES. C., GREENHALGH, C. 'A comparison of the use and value of patents and trade-marks in large and small firms'. Oxford, UK: Oxford Intellectual Property Research Centre, 2007.

SAMPIERI, R. et al. Metodología de la investigación. 2010.

SAUERBRONN, J. F. R.; SAUERBRONN, F. F.; HASENCLEVER, Lia. Contribuições da economia industrial para o estudo de estratégias de crescimento a partir do sistema de franquia. Revista Economia \& Gestão, v. 11, n. 26, p. 33-61, 2011.

SMITH, K. G., TERENCE R. M., CHARLES E. S. "Top level management priorities in different stages of the organizational life cycle." Academy of management Journal 28.4 799-820, (1985).

SCOTT, B. "Stages of Corporate Development-Parts I and II," Working Paper, Harvard Business School. Boston: 1970.

TRAUTWEIN, F. Merger motives and merger prescriptions. Strategic management journal, v. 11, n. 4, p. 283-295, 1990. 
TRIPODI, T.; FELLERS, P. W.; MEYER, H. J. Análise da pesquisa social diretrizes para o uso de pesquisa em serviço social e ciências sociais. F. Alves, 1981.

VAN DE VEN, A. H.; HUDSON, R.; SCHROEDER, D. M. Designing new business startups: Entrepreneurial, organizational, and ecological considerations. Journal of management, v. 10, n. 1, p. 87-108, 1984.

WILLIAMSON, O. E. The economic institutions of capitalism: firms, markets, relational contracting. New York: Free Press, 1985.

WHETTEN, D. A. (1987). Organizational growth and decline processes. Annual review of sociology, 13(1), 335-358.

ZHOU, H.; DE WIT, G. Determinants and dimensions of firm growth. SCALES EIM Research Reports, 2009. 